\title{
Does Sternal Cable System Prevent Sternal Complications after Revision Sternal Surgery?
}

\author{
Levent Altınay ${ }^{1}$, Elif Coşkun Sungur ${ }^{2}$, Anil Özen², Anıl Tekin³ ${ }^{3}$ Sıtkı Akın Turan, Görkem Yiğit ${ }^{2}$ and Ufuk Tütün ${ }^{3}$ \\ ${ }^{1}$ Department of Cardiovascular Surgery, Dlşkapı Education and Research Hospital, Ankara, Turkey \\ ${ }^{2}$ Department of Cardiovascular Surgery, Ankara City Hospital, Ankara, Turkey \\ ${ }^{3}$ Department of Cardiovascular Surgery, Faculty of Medicine, Bülent Ecevit University, Zonguldak, Turkey
}

\begin{abstract}
Objective: To determine the efficacy of a sternal wire system in secondary sternal dehiscence after repeat closure of the sternum, following surgical revision after open heart surgery.

Study Design: Case-control study.

Place and Duration of Study: Department of Cardiovascular Surgery, Zonguldak Bülent Ecevit University, Zonguldak, Turkey; and Turkey Yuksek Ihtisas Training and Research Hospital, Turkey, from January 2015 to May 2019.

Methodology: Patients, who underwent open heart surgery with median sternotomy, were included in this retrospective study. The patients were divided into two groups, according to the sternal closure material. The time of the sternal reconstruction surgery, because of sternal dehiscence, fracture, broken sternal wire(s) or cable(s) after the first revision surgery, was noted for each patient.

Results: A total of 389 patients were identified. Group 1 included 72 (50\%) patients whose sternums were closed with a sternal cable system; and Group 2 included $72(50 \%)$ patients whose sternums were closed with conventional steel wires after propensity matching. The duration of cardiopulmonary bypass, number of intra-aortic balloon pumps used, and number of extracorporeal membrane oxygenators used were significantly higher in Group 1 ( $p=0.007, p=0.034$, and $p$ $=0.028$, respectively). The number of emergency operations was significantly higher in Group $2(p=0.021)$. There was no significant difference in terms of secondary sternal dehiscence between the groups $(p=0.366)$.

Conclusion: Application of the sternal wire system in revisional open heart surgery is not more effective than conventional steel wire at preventing secondary sternal dehiscence.
\end{abstract}

Key Words: Sternal dehiscence, Sternal cable, Sternal wire, Open heart surgery, Postoperative revision.

How to cite this article: Altınay L, Sungur EC, Özen A, Tekin A, Turan SA, Yiğit G, Tütün U. Does Sternal Cable System Prevent Sternal Complications after Revision Sternal Surgery?. J Coll Physicians Surg Pak 2021; 31(09):1069-1074.

\section{INTRODUCTION}

Median sternotomy has been the standard technique of cardiac exposure in open heart surgery for decades. The anatomy of the mediastinum can be exposed quickly by median sternotomy, it provides access to major vasculature in the mediastinum for central cannulation during cardiopulmonary bypass, and it is well tolerated by patients. Post-sternotomy healing complications, such as sternal wound infection and dehiscence, occur in about $0.5 \%$ to $5 \%$ of patients after cardiac surgery. Mortality rates related to these complications are reported to be between $15 \%$ and $50 \%{ }^{1,2}$

Correspondence to: Dr. Görkem Yiğit, Department of Cardiovascular Surgery, Ankara City Hospital, Ankara, Turkey

E-mail: drgorkemyigit@gmail.com

Received: April 05, 2021; Revised: August 16, 2021;

Accepted: August 26, 2021

DOI: https://doi.org/10.29271/jcpsp.2021.09.1069
The treatment costs of patients with sternal wound complications are approximately 2.8 times higher than patients without sternal wound complications. ${ }^{2}$ The high-price sternum closure materials used in these patients contribute to the high costs.

There are many techniques for sternal closure, described in the literature; and many studies conducted about primary closure techniques of the sternum after open heart surgery; ${ }^{3-6}$ but there are no studies focused on the secondary dehiscence of the sternum after repeat closure following surgical revision to the best of authors' knowledge.

Herein, the aim was to determine the effect of a sternal wire system on secondary sternal dehiscence after repeat closure of the sternum, following surgical revision in patients who underwent open heart surgery.

\section{METHODOLOGY}

Patients who underwent open heartsurgery with median sternotomy at Zonguldak Bülent Ecevit University, Zonguldak, 
Turkey; and Turkey Yuksek Ihtisas Training and Research Hospital, Turkey, from January 2015 to May 2019, were evaluated in this retrospective study. Open heart and aortic surgeries without median sternotomy (with lateral thoracotomy, etc.), redo surgeries, sternal closure with any means other than a sternal cable system, and sternal wire were the exclusion criteria.

Patients were divided into two groups. Group 1 was the study group and included patients who underwent an early postoperative revision surgery and whose sternums were closed with a sternal cable system (RTI surgical cable system, pioneer surgical technology, Inc., Marquette, Michigan, USA). Group 2, as the control group, included patients whose sternums were closed with conventional steel wires (LVM stainless steel surgical cables), The time of the sternal reconstruction surgery because of a sternal healing complications, such as sternal dehiscence, sternal fracture, broken sternal wire(s) or cable(s), was noted foreach patient.

A sternal cable system was used for sternal closure in these situations: if the patient was over 70 years, had diabetes and obesity (body mass index $(\mathrm{BMI})>30$ ), had bilateral internal mammary artery (IMA) graft harvesting performed or, had chronic obstructive pulmonary disease (COPD) or chronic kidney disease (CKD). The final decision for sternal cable application was made by the operating surgeon after the evaluation of the patient's sternal bone structure.

Revision surgery, performed within the first 24 hours postoperatively, is defined as early revision surgery. The decision for early postoperative revision surgery was made by the same surgeon who had performed the initial operation. Early postoperative bleeding and/or cardiac tamponade were accepted as the primary indications for early postoperative revision surgery. ${ }^{7}$

All patients wore sternal support vests (Orthocare sternicare plus $^{\mathrm{TM}}$, Ankara, Turkey) during the hospitalisation period and were discharged with these supportive vests with recommendations on continuous wearing of these vests during the day, wound care, body hygiene and precautions to prevent sternal dehiscence.

Secondary sternal dehiscence is defined as the presence of broken sternal wire(s) orcable(s) documented in the antero-posterior and lateral chest radiogrammes, causing sternal dehiscence in physical examination after the primary revision surgery.

The sternal revision surgery was performed in the presence of sternal dehiscence in physical examination and sternal bone and wire fracture in the chest radiogram accompanied by superficial wound infection and severe complaints and discomfort of patients related with these sternal complications observed in the outpatient clinic follow-ups. Local ethical committee approval was obtained for data collection and study conduction. The study complied with the Declaration of Helsinki and its later amendments.
All of the primary operations were performed under general anaesthesia and with median sternotomy incision. Conventional cardiopulmonary bypass (CPB) with cardioplegia, onpump beating heart (ONBHCAB) or off-pump (OPCAB) techniques were utilised with regard to the type of surgery and to patient-related attributes, such as left ventricle dysfunction, comorbidities, emergent surgery, etc. Sternotomy was closed either with a sternal cable system or sternal steel wires. Figureof-8 and simple wire loop wiring techniques were used for sternal wire and cable application, according to the decision of the surgeon. Four figure-of-8 or minimum five simple wire/cable loops were placed according to the anatomy and structure of the patient'ssternum.

Early postoperative revision operations were performed without CPB. Secondary sternal closure technique and material were chosen by the operating surgeon, regardless of the initial sternal closure system.

The statistical analysis of the data was done with statistical package for the social sciences (SPSS version 16.0 Inc., Chicago, IL, USA) software. Categorical data were expressed as numbers and percentages. Continuous data were presented as mean \pm standard deviation (SDs). The Kolmogorov-Smirnov test was used to test the normality of the data distribution. In order to decrease the effect of selection bias and potential confounding, propensity score matching was performed using a one-to-one matching ratio and nearest neighbour matching algorithm. The propensity scores of the preoperative baseline characteristics variables were calculated using logistic regression analysis. The adequacy of the propensity score model was evaluated using the area under the ROC curve (C-index) and the Hosmer-Lemeshow goodness-of-fit test. The model yielded a Cindex value of 0.752 and a Hosmer-Lemeshow goodness-of-fit Chi-square value of $1.63(p=0.990)$, which indicated that the model was well-calibrated. The categorical data were tested with the Chi-square and Fisher's Exact tests and the continuous data were tested with the independent samples t-test. P values $<0.05$ were considered as statistically significant.

\section{RESULTS}

A total of 389 patients, who had a median sternotomy, were identified. A total of 72 patients, who underwent early postoperative revision surgery and had their sternotomy closed with a cable system, were included in Group 1 as the study group; and their propensity score-matched pairs 72 patients who had their sternotomy closed with conventional steel wires, were included in Group 2 as the control group. The preoperative demographic characteristics are presented in Table I.

Postoperative data are presented in Table II. The duration of CPB was longer in Group 1 ( $p=0.007)$. More patients needed intraaortic balloon pump counter pulsation in the postoperative period in Group 1 ( $p=0.034)$. More patients needed extracorporeal membrane oxygenation (ECMO) support in the postoperative period in Group 1 ( $p=0.028$ ). The number of emergency operations wassignificantly higherin Group $2(p=0.021)$. 
Table I: Preoperative demographic data of the initial procedures (propensity matched).

\begin{tabular}{|c|c|c|c|}
\hline & Group $1(n=72)$ & Group $2(n=72)$ & p-value \\
\hline Male & $37(51.39)$ & $29(40.28)$ & 0.181 \\
\hline Age (Mean \pm SD) & $64.21 \pm 12.46$ & $63.92 \pm 10.62$ & 0.880 \\
\hline BMI (Mean \pm SD) & $29.92 \pm 4.55$ & $29.83 \pm 4.17$ & 0.905 \\
\hline Preoperative EF & $50.17 \pm 8.31$ & $49.30 \pm 9.36$ & 0.557 \\
\hline Hypertension & $50(69.44)$ & $50(69.44)$ & $>0.999$ \\
\hline Hyperlipidemia & $16(22.22)$ & $22(30.56)$ & 0.257 \\
\hline COPD & $15(20.83)$ & $15(20.83)$ & $>0.999$ \\
\hline Diabetes mellitus & $38(52.78)$ & $36(50.00)$ & 0.739 \\
\hline \multicolumn{3}{|l|}{ Medication for diabetes } & 0.484 \\
\hline None & $33(46.48)$ & $38(52.78)$ & \\
\hline OAD & $21(29.58)$ & $14(19.44)$ & \\
\hline Insulin & $11(15.49)$ & $15(20.83)$ & \\
\hline OAD + Insulin & $6(8.45)$ & $5(6.94)$ & \\
\hline Tobacco product smoking & $30(42.25)$ & $29(40.28)$ & 0.810 \\
\hline Thyroid gland dysfunction & $9(12.50)$ & $8(11.27)$ & 0.820 \\
\hline \multicolumn{3}{|l|}{ CKD stage } & 0.121 \\
\hline \begin{tabular}{|l|l|} 
Stage 1 \\
\cline { 2 - 2 }
\end{tabular} & $16(22.22)$ & $28(38.89)$ & \\
\hline Stage 2 & $41(56.94)$ & $30(41.67)$ & \\
\hline Stage 4 & $3(4.17)$ & $1(1.39)$ & \\
\hline Stage 5 & 0 & $1(1.39)$ & \\
\hline \begin{tabular}{|l|l} 
Stage 3a \\
\end{tabular} & $11(15.28)$ & $9(12.50)$ & \\
\hline \begin{tabular}{|l|l} 
& Stage 3b \\
\end{tabular} & $1(1.39)$ & $3(4.17)$ & \\
\hline \multicolumn{3}{|l|}{ Preoperative diagnosis } & 0.628 \\
\hline CAD & $47(65.28)$ & $54(75)$ & \\
\hline CAD + HVD & $2(2.78)$ & $2(2.78)$ & \\
\hline CAD + Carotid & $3(4.17)$ & $1(1.39)$ & \\
\hline HVD & $10(13.89)$ & $6(8.33)$ & \\
\hline Aorta disease & $10(13.89)$ & $9(12.50)$ & \\
\hline
\end{tabular}

More patients needed inotropic agent support (adrenaline, dopamine or dobutamine) in the intensive care unit followup period in Group 1; but it was not statistically significant $(p=0.062)$. There was no significant difference in terms of secondary sternal dehiscence between the groups $(p=$ 0.366).

One patient had sternal cable rupture in Group 1 without sternal bone fracture two months after his sternal revision surgery.

\section{DISCUSSION}

The results of this study show that the rate of secondary sternal dehiscence after the early revision surgery is not affected by the sternal closure material, which is either wire or cable.

There are many risk factors related to postoperative sternal complications such as diabetes, obesity (BMI $>30$ ), older age
(>75 years), CKD, postoperative revision surgery, harvesting bilateral IMA grafts, COPD and prolonged CPB ${ }^{8,9}$ In this study, the mean CPB time of the study group (Group 1) was significantly higher than the control group (Group 2); but the secondary dehiscence rates were similar.

Nezafati et al. used sternal implants to fix the sternum in 168 patients and compared the 12-month follow-up results of 158 patients with conventional sternal steel wires. ${ }^{4}$ They reported better results with the sternal implants in terms of pain and sternal dehiscence, but had non-significant results in terms of sternal wound infection. Marasco et al. used the same sternal closure implants as the aforementioned study in their prospective randomized study including 118 patients. ${ }^{10}$ They compared these implants and steel wires in terms of sternal movement and reported significantly more movement of the sternum and manubrium in the implant group. Both authors did not use the device on the secondary closure of the sternum and did not have any experience of the re-application of the device.

Table II: Postoperative data of the initial procedures.

Table II: Postoperative data of the initial procedures.
\begin{tabular}{|l|c|c|c|}
\hline & Group 1 (n=72) & Group 2 (n=72) & p-value \\
\hline Emergency primary operation & $6(8.33)$ & $16(22.22)$ & 0.021 \\
\hline
\end{tabular}




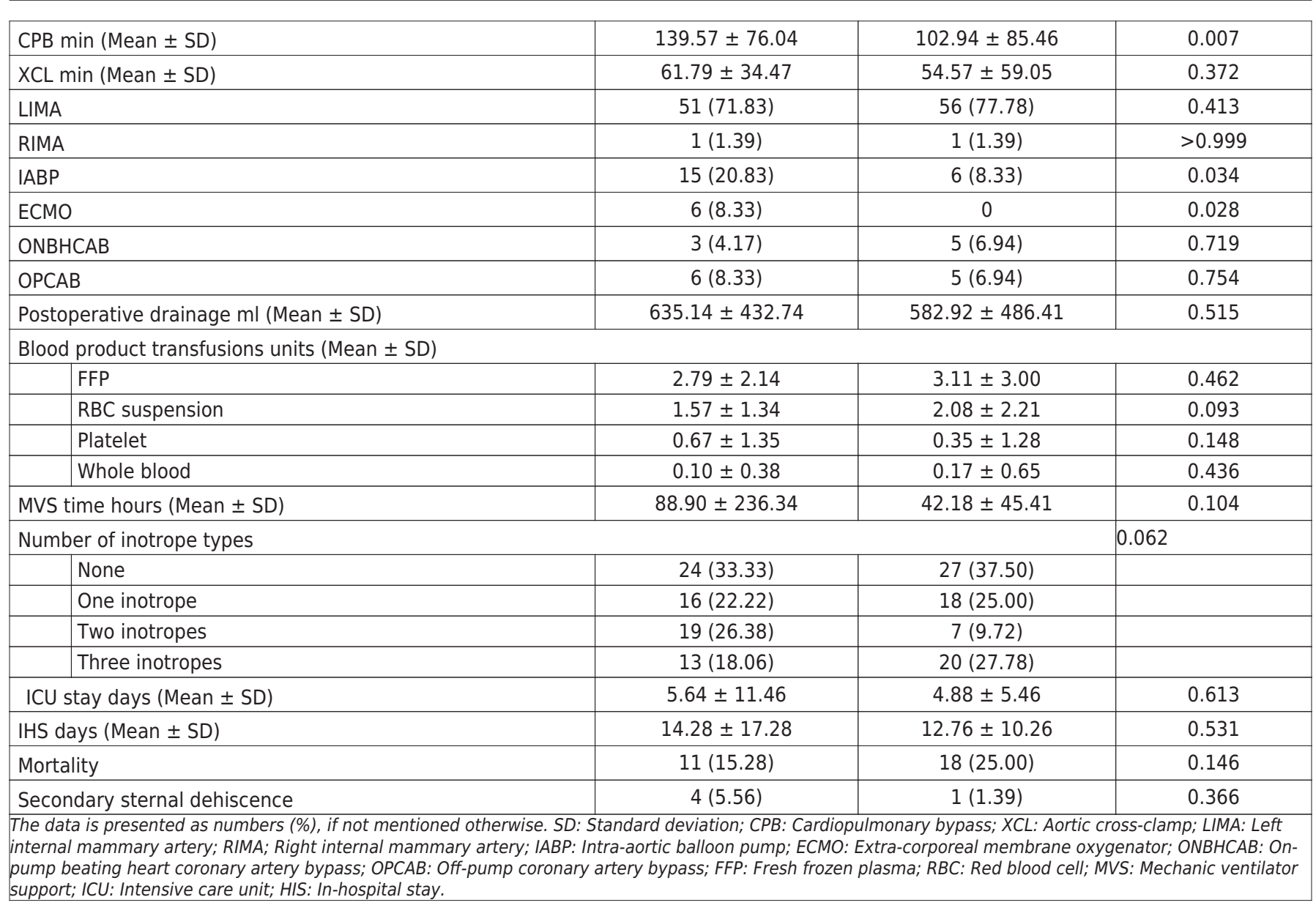

Tunçay et al. used sternal clips to close the sternotomy of six patients with non-infectious sternal dehiscence. ${ }^{11}$ They reported better outcomes and the cost-effectiveness of these clips as compared to conventional sternal wire closure, but they did not provide any data about the comparison of the costs of the device and the sternal wire. Moreover, they did not use the device on secondary sternal closure and had no data about the re-utilization of the device.

Dunne et al. and Oh et al. used the same cable system as the one used in this study. ${ }^{6,12}$ Dunne et al. enrolled 273 patients and found non-significant differences between the results of cable and wire groups in terms of sternal wound infection. Oh et al. conducted their study on 392 patients and reported the cable system had no better clinical results than the conventional steel wire. ${ }^{12}$ They did not use the cable system on secondary sternal closure.

Another method for sternal closure is, using the combination of the materials and systems in the market. Ata et al. used a sternal cable system and conventional steel wires in combination when closing the sternotomy in obese patients (BMI > 30) undergoing open heart surgery. ${ }^{13}$ They reported a decrease in the incidence of sternal dehiscence in these patients.

In the recent guidelines for CABG surgery and meta-analyse of the largest clinical trials, total arterial revascularisation of the myocardium is a favourable technique. ${ }^{14,15}$ But the main concern about total arterial revascularisation is the risk of sternal wound infection and dehiscence requiring reoperation after bilateral IMA graft harvesting. ${ }^{16}$ The present authors think that the pros and cons should be well weighed before harvesting bilateral IMA grafts, especially in high risk patients (i.e. diabetics, obese, and patients with COPD); and if bilateral IMA graft harvesting is mandatory, conventional steel wires and high-price sternal cable devices can be considered as equals with regard to the incidence of postoperative sternal complications.

External support vests help keep the sternum intact and reduce the mechanical complications of sternal healing in the postoperative period. In their prospective randomised trial, Caimmi et al. reported better sternal healing, ${ }^{17}$ lower incidence of mechanical sternal complications, shorter hospital stay, and better quality of life in patients using external support vests. Vos et al. also reported a significant reduction in deep sternal wound infections in patients using support vests. ${ }^{18}$

In this study, the sternal cable system was used in patients who had revision surgery because of postoperative sternal complications regardless of the primary sternal closure technique. In the authors' experience, the removal of the cable 
system was as easy as removing the sternal wires and re-application of the cable system was as easy as the first-time application.

The study was conducted retrospectively, which was a major limitation, but propensity score matching and building a model according to the propensity score were performed to overcome selection bias. It is not possible to have full knowledge of the patients' behaviours and how well they follow the recommendations on sternal care-taking precautions after they are discharged, so it is not possible to define the effect of the patients' behaviours on the occurrence of sternal dehiscence. Preoperative sternal bone densitometry and evaluation of patients for osteoporosis were not available because of technical difficulties.

\section{CONCLUSION}

Application of the sternal wire system in revisional open heart surgery is not more effective than conventional steel wires at preventing secondary sternal dehiscence. The authors think that more studies should be conducted to evaluate its related risk factors.

\section{ETHICAL APPROVAL:}

This study was conducted with the approval from the Ethics Committee of the Zonguldak Bülent Ecevit University, Turkey (Registry No. 2019-146-18/09).

\section{PATIENT'S CONSENT:}

No informed consent was taken, because the study was conducted with retrospective data collection technique.

\section{CONFLICT OF INTEREST:}

The authors declared no conflict of interest.

\section{AUTHORS' CONTRIBUTION:}

LA, EC: Data acquisition, interpretation and drafting.

AÖ: Analysis, critical revision and final approval.

AT: Conception and design.

GY: Analysis and interpretation.

UT: Final approval.

\section{REFERENCES}

1. Casha AR, Yang L, Kay PH, Saleh M, Cooper GJ. A biomechanical study of median sternotomy closure techniques1. Eur J Cardio-Thoracic Surg 1999; 15(3):365-9. doi.org/10.1016/ S1010-7940(99)00014-7.

2. Loop FD, Lytle BW, Cosgrove DM, Mahfood S, McHenry MC, Goormastic M, et al. J. Maxwell Chamberlain memorial paper. Sternal wound complications after isolated coronary artery bypass grafting: Early and late mortality, morbidity, and cost of care. Ann Thorac Surg 1990; 49(2):179-86; discussion 186-7. doi: 10.1016/0003-4975(90)90136-t.

3. Özen Y. Comparison of the sternal wires and sternal cable in closure of the sternum during cardiac surgery. Cardiovasc Surg Interv 2015; 1:41-4.

4. Nezafati P, Shomali A, Kahrom M, Omidvar Tehrani S,
Dianatkhah M, Nezafati MH. Zipfix versus conventional sternal closure: One-year follow-up. Hear Lung Circ 2019; 28(3):443-9. doi: 10.1016/j.hlc.2018.01.010.

5. Elghonemy YF, Hussein MA. Titanium plate fixation versus wire sternal closure in coronary artery bypass graft patients: Need for rigid sternal fixation. J Egypt Soc CardioThoracic Surg 2016; 24(2):150-8. doi.org/10.1016/ j.jescts.2016.06.003.

6. Dunne B, Murphy M, Skiba R, Wang X, Ho K, Larbalestier R, et al. Sternal cables are not superior to traditional sternal wiring for preventing deep sternal wound infection. Interact Cardiovasc Thorac Surg 2016; 22(5):594-8. doi: 10.1093/ icvts/ivw017.

7. Adler $Y$, Charron $P$, Imazio M, Badano L, Barón-Esquivias G, Bogaert J, et al. 2015 ESC Guidelines for the diagnosis and management of pericardial diseases. Eur Heart J 2015; 36(42):2921-64. doi: 10.1093/eurheartj/ehv479.

8. Fowler VG, O'Brien SM, Muhlbaier LH, Corey GR, Ferguson TB, Peterson ED. Clinical predictors of major infections after cardiac surgery. Circulation 2005; 112(9):1358-65. doi: 10.1161/CIRCULATIONAHA.104.525790.

9. Losanoff J. Disruption and infection of median sternotomy: A comprehensive review. Eur J Cardio-Thoracic Surg 2002; 21(5):831-9. doi: 10.1016/s1010-7940(02)00124-0.

10. Marasco SF, Fuller L, Zimmet A, McGiffin D, Seitz M, Ch'ng $S$, et al. Prospective, randomised, controlled trial of polymer cable ties versus standard wire closure of midline sternotomy. J Thorac Cardiovasc Surg 2018; 156(4): 1589-95.e1. doi: 10.1016/j.jtcvs.2018.04.025.

11. Tunçay A, Akçalı YF, Özmen R, Gazioğlu Ö, Serhatlıoğlu F. Vitalitec International, The sternal closure device: A novel closure technique for sternal dehiscence. J Clin Exp Investig 2014; 5:534-8.

12. Oh YN, Ha KJ, Kim JB, Jung S-H, Choo SJ, Chung CH, et al. Multifilament cable wire versus conventional wire for sternal closure in patients undergoing major cardiac surgery. Korean J Thorac Cardiovasc Surg 2015; 48(4): 265-71. doi: 10.5090/kjtcs.2015.48.4.265.

13. Ata $Y$, Aydın U, As AK, Özsin KK, Fındık O, Türk T. Sternal cable wires for sternal closure in moderately or extremely obese patients undergoing cardiac surgery. Eur Res J 2018; 4:308-13.

14. Neumann FJ, Sousa-Uva M, Ahlsson A, Alfonso F, Banning AP, Benedetto U, et al. 2018 ESC/EACTS Guidelines on myocardial revascularization. Eur Heart J 2019; 40(2): 87-165. doi: 10.1093/eurheartj/ehy394.

15. Gaudino M, Lorusso R, Rahouma M, Abouarab A, Tam DY, Spadaccio $C$, et al. Radial artery versus right internal thoracic artery versus saphenous vein as the second conduit for coronary artery bypass surgery: A network meta-analysis of clinical outcomes. J Am Heart Assoc 2019; 8(2):e010839. doi: 10.1161/JAHA.118.010839.

16. Taggart DP, Benedetto U, Gerry S, Altman DG, Gray AM, Lees $B$, et al. Bilateral versus Single Internal-thoracic-artery grafts at 10 years. $N$ Engl J Med 2019; 380(5):437-6. doi: 10.1056/NEJMoa1808783.

17. Caimmi PP, Sabbatini M, Kapetanakis El, Cantone S, Ferraz M V., Cannas M, et al. A Randomized trial to assess the contribution of a novel thorax support vest (Corset) in 
preventing mechanical complications of median sternotomy. Cardiol Ther 2017; 6(1):41-51. doi: 10.1007/ s40119-016-0078-y.
18. Vos RJ, Van Putte BP, Kloppenburg GTL. Prevention of deep sternal wound infection in cardiac surgery: A literature review. J Hosp Infect 2018; 100(4):411-20. doi: 10.1016/ j.jhin.2018.05.026. 